\title{
Cost-Effectiveness of Different Forms of Intra-Articular Injections for the Treatment of Osteoarthritis of the Knee
}

Jeffrey Rosen · Parag Sancheti · Anke Fierlinger · Faizan Niazi •

Herman Johal · Asheesh Bedi

Received: March 7, 2016 / Published online: May 4, 2016

(c) The Author(s) 2016. This article is published with open access at Springerlink.com

\begin{abstract}
Introduction: Osteoarthritis (OA), as one of the leading causes of disability, decreases the quality of life for those suffering from the disease and creates a substantial financial burden. Intra-articular hyaluronic acid (HA) can provide relief from the symptoms of OA and multiple HA products are prescribed. The purpose of this study is to examine the single
\end{abstract}

Enhanced content To view enhanced content for this article go to www.medengine.com/Redeem/71C4F0600 D05049E.

Electronic supplementary material The online version of this article (doi:10.1007/s12325-016-0331-8) contains supplementary material, which is available to authorized users.

J. Rosen $(\bowtie)$

Department of Orthopaedics and Rehabilitation,

New York Presbyterian Queens, New York, USA

e-mail: rosenje@nyp.org

J. Rosen

Department of Orthopaedic Surgery and

Rehabilitation, Weill Medical College of Cornell

University, New York, USA

P. Sancheti

Sancheti Institute for Orthopaedics and

Rehabilitation, Maharashtra, India payer cost-effectiveness of various HA products in the treatment of knee OA.

Methods: A single payer economic evaluation was conducted comparing Synvisc ${ }^{\circledR}$ (Sanofi, USA), Durolane ${ }^{\circledR}$ (Bioventus, USA), Hyalgan ${ }^{\circledR}$ (Fidia Pharma Inc., USA), Supartz ${ }^{\mathrm{TM}}$ (Bioventus, USA), and Euflexxa ${ }^{\circledR}$ (Ferring Pharmaceuticals Inc., USA). Utility scores for HA products were obtained by extracting Western Ontario and McMaster Universities Arthritis Index pain, stiffness and function from randomized controlled trials and converting them to health utilities index mark 3 scores. The cost of a treatment included the cost of the HA injection, cost of a knee injection procedure and cost of a doctor's visit for each required injection. Cost-utility in 2015 USD per quality-adjusted life years (QALY) saved was

\footnotetext{
A. Fierlinger · F. Niazi

Ferring Pharmaceuticals Inc., Parsippany, NJ, USA

H. Johal

Division of Orthopaedics, Department of Surgery, Centre for Evidence-Based Orthopaedics, McMaster University, Hamilton, ON, USA

A. Bedi

Department of Orthopaedic Surgery, University of Michigan, Ann Arbor, MI, USA
} 
calculated for each HA product, and incremental cost-effectiveness ratios were calculated to compare the effectiveness of HA products to one another and to conventional care.

Results: When compared to conventional care, all investigated HA products were cost-effective, assuming a willingness-to-pay threshold of $\$ 50,000 /$ QALY gained. The HA product Euflexxa had the most favorable cost-utility ratio (\$5785.52/QALY) when compared to all other HA brands.

Conclusion: The present study showed several HA products to be cost-effective in comparison to conventional care, with Euflexxa having the most favorable cost/QALY gained ratio compared to the other HA products.

Funding: Ferring Pharmaceutics Inc.

Keywords: Cost-effectiveness; $\quad$ Euflexxa; Hyaluronic acid; Knee; Osteoarthritis

\section{INTRODUCTION}

As one of the leading causes of disability, osteoarthritis (OA) decreases overall quality of life for those suffering from the disease and represents a substantial financial burden on the economy [1, 2]. The direct and indirect costs of arthritis were estimated to be $\$ 126$ billion in the United States in 2003, and with the prevalence of the disease rising, these values will only continue to increase $[3,4]$. With prevalence and costs related to OA trending upwards, the need to find cost-effective management strategies to control the impact of the disease on patient quality of life becomes increasingly important.

During the early stages of knee OA, conservative management including weight loss, the use of ambulatory aids, simple analgesics and nonsteroidal anti-inflammatory drugs (NSAIDS) is the first line of treatment; however, as the disease progresses and the joint becomes increasingly painful, the effectiveness of these treatment options becomes limited [5]. By the end stages of OA, total knee arthroplasty (TKA) is often necessary to address the degradation of the joint and the associated symptoms which severely limit day-to-day function [5]. TKA procedures are costly, with an inpatient TKA costing approximately $\$ 20,000$, and a revision TKA costing approximately $\$ 25,000$ [6]. The total cost for all TKA procedures in the US for 2012 was over $\$ 11$ billion [7]. The younger a patient is when undergoing primary TKA, the more likely that a revision TKA will be necessary in the future [8]. Therefore, it is important to use adjunct treatment methods to delay the progression of disease symptoms and bridge the gap to costly arthroplasty procedures.

Intra-articular (IA) hyaluronic acid (HA) injections have been used to relieve symptoms of knee OA and have the potential to delay the need for TKA $[9,10]$. There is a general lack of understanding about the intrinsic properties of various IA-HA products and the effect they have on overall effectiveness. Evidence has demonstrated an increased efficacy of high molecular weight (HMW) HA products over low molecular weight HA products, and improved safety outcomes of biological fermentation-derived HA products (Bio) compared to avian-derived HA products [11, 12]. While there is uncertainty regarding the differences in intrinsic properties of IA-HA products compared to one another, even less is known regarding their cost-effectiveness.

While previous literature has examined the individual cost-effectiveness of specific IA-HA products, previous studies have not compared the cost-effectiveness across several IA-HA products [13, 14]. Therefore, the purpose of 
this study is to examine and compare the cost-utility of different IA-HA products relative to conventional care, as well as to one another.

\section{METHODS}

\section{Treatment Utility Scores}

Utility scores for the treatments were determined by converting Western Ontario and McMaster Universities Arthritis Index (WOMAC) scores to health utilities index mark 3 (HUI-3) scores using the model proposed by Grootendorst et al. [15]. WOMAC scores were obtained from the results of a systematic search using the MEDLINE database. Titles, abstract and full articles were screened and studies were included if they were randomized controlled trials examining the use of IA-HA in knee OA, and reported full WOMAC pain, stiffness and functional outcomes at baseline and 6 months following treatment.

The systematic search yielded 271 studies, of which five randomized controlled studies examining five IA-HA products had sufficient WOMAC pain, stiffness and functional outcome data at both baseline and 6-month follow-up. The products used in the comparisons were Synvisc ${ }^{\circledR}$ (Sanofi, Bridgewater, NJ, USA) [16], Durolane $^{\circledR}$ (Bioventus, Durham, NC, USA) [17], Hyalgan $^{\circledR}$ (Fidia Pharma Inc., Parsippany, NJ, USA) [18], Supartz ${ }^{\circledR}$ (Bioventus, Durham, NC, USA) [16, 19], and Euflexxa ${ }^{\circledR}$ (Ferring Pharmaceuticals Inc., Parsippany, NJ, USA) [20]. A summary of product characteristics is provided in Supplementary Appendix A. The quality of the studies was assessed using the Cochrane Collaborations tool for assessing risk of bias [21]. Four of the five studies involved industry funding, yet the role of the funding source in the involvement of the study was not disclosed (Table 1). No other potential high sources of bias were identified within the included studies.

We extracted WOMAC scores reported in the five-point Likert format, as the Grootendorst models cannot be used for WOMAC scores reported in the $100 \mathrm{~mm}$ Visual Analog Scale (VAS) format [15]. Utility scores for Euflexxa were abstracted from Hatoum et al. [14] using Engauge Digitizer (version 4.1, open-source, non-commercial product). The utility score data for conventional care were acquired from Raynauld et al. [22], which provided WOMAC pain, stiffness and physical function scores for treatment with NSAIDS, physiotherapy, acetaminophen and assistive devices.

\section{Treatment Cost Data}

A single payer perspective was taken with respect to costs. Costs for treatments were obtained through the Centres for Medicare and Medicaid Services Fees Schedule and a wholesale supplier database [23, 24]. All costs were in 2015 USD. Treatment costs included IA-HA product, physician visit (\$43.98 USD), injectable drug administration (\$61.14 USD) for each injection that the treatment course required and the cost of additional conventional care (\$321.5 per 6 months) as non-operative treatment of knee $\mathrm{OA}$ is generally multi-modal [2]. Cost data for conventional care was obtained from Losina et al. who determined the cost of treatment with conservative measures, which was then divided into half to determine the treatment cost for 6 months [2]. For example, a three-injection course would require the cost for the initial physician visit and three injectable drug administrations [23]. The cost of each treatment for 6 months was, therefore, calculated by the formula: 


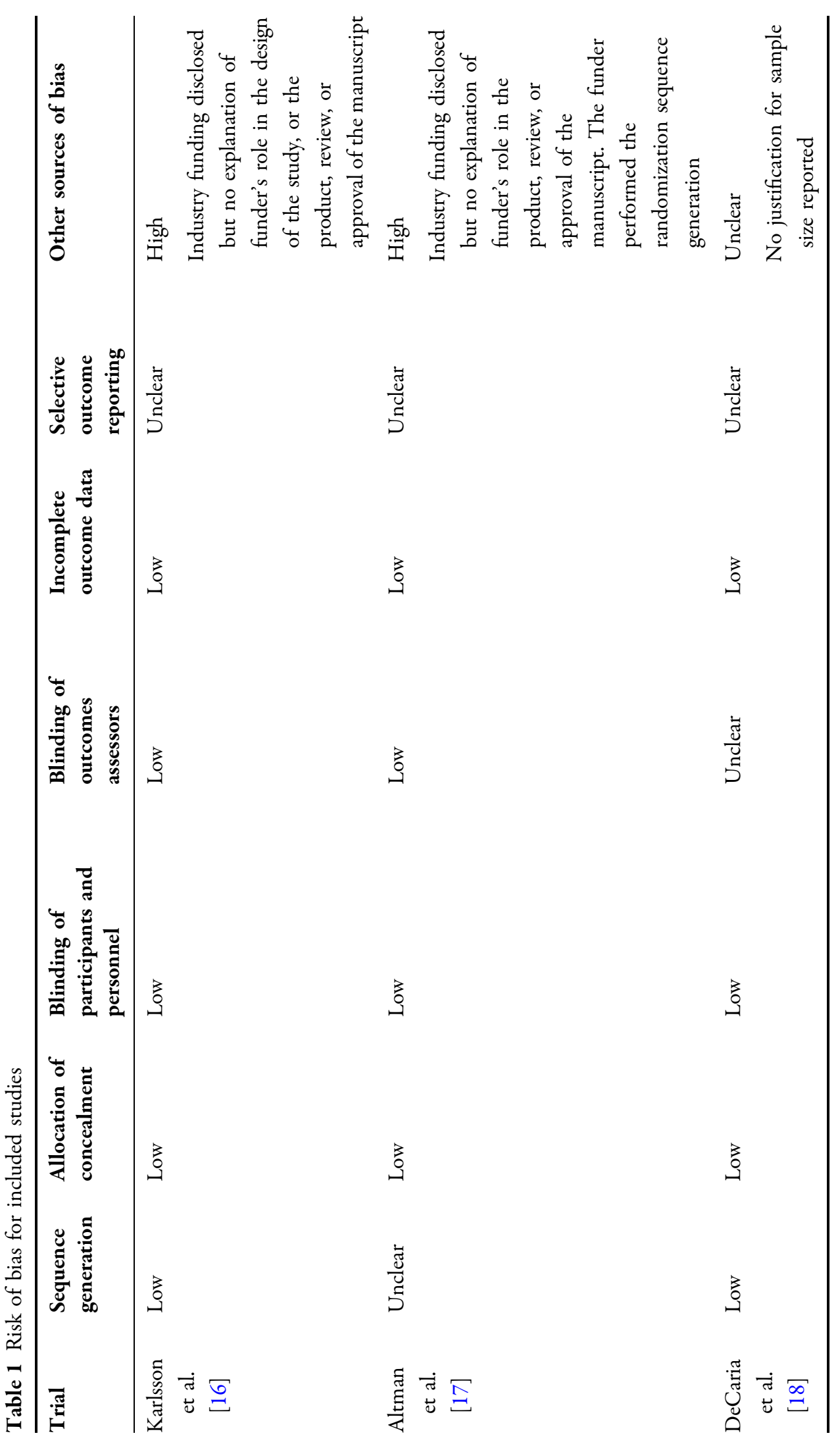




$$
1
$$




$$
\begin{aligned}
\text { Treatment cost }= & \text { IA }- \text { HAProductcost }+\$ 43.98 \\
& +(\# \text { of injections } * \$ 61.14) \\
& + \text { Cost of conventional care }
\end{aligned}
$$

\section{Cost-Utility Analysis}

Cost-utility ratios were valued as the cost per quality-adjusted life years (QALY) gained. To determine the number of QALY gained by the treatment, the average baseline utility score of a given treatment was subtracted from the average 6-month post-treatment utility score, with the assumption that if participants had not received the treatment, there would be no QALY gained or lost through the 6-month period, and no cost would be incurred as they did not receive any treatment.

Incremental cost-effectiveness ratios (ICERs) were determined to compare the treatment options with one another. These were calculated using the formula $\left(\mathrm{C}_{B}-\mathrm{C}_{\mathrm{A}}\right)$ / $\left(Q_{B}-Q_{A}\right)$, where $C_{B}$ and $C_{A}$ represent the cost of treatment $\mathrm{B}$ and treatment $\mathrm{A}$, respectively, and $\mathrm{Q}_{B}$ and $\mathrm{Q}_{\mathrm{A}}$ represent the QALY gained for treatment $\mathrm{B}$ and treatment $\mathrm{A}$, respectively. A treatment is considered cost-effective if it falls below the willingness-to-pay threshold, which has ranged from $\$ 50,000 / \mathrm{QALY}$ to $\$ 150,000 /$
QALY in the literature, and is considered dominant if it is both more effective and less costly compared to the alternative $[25,26]$. For the purpose of this study, a willingness-to-pay threshold of $\$ 50,000 /$ QALY was chosen, as this is the most conservative estimate. The ICERs of all treatments were calculated compared to conventional care, as well as to the IA-HA product yielding the greatest effect with respect to QALY gained. Data abstraction and analysis was conducted using Microsoft Excel (Version 2010, Microsoft, Redmond, WA, USA).

\section{Sensitivity Analyses}

A one-way sensitivity analysis was performed to determine the robustness of the results and was performed in each of the stepwise analyses performed in this study. For the cost-utility of each individual product, sensitivity analyses were performed by changing the price of treatment by $\pm 20 \%$, and by changing the utility score of the treatment by $\pm 20 \%$. When determining the difference in cost-utility of products in comparison to conventional care and to one another, the costs and utility scores of the HA products were once again adjusted for sensitivity analysis by $\pm 20 \%$ before the ICER was performed.

Table 2 Utility Scores

\begin{tabular}{llll}
\hline Brand & Baseline utility score & $\begin{array}{l}\text { 6-month post-treatment } \\
\text { utility score }\end{array}$ & $\begin{array}{l}\text { QALY gained/ } \\
\text { 6 months }\end{array}$ \\
\hline Euflexxa [20] & 0.482 & 0.627 & 0.145 \\
Synvisc [16] & 0.561 & 0.685 & 0.124 \\
Supartz [16, 19] & 0.609 & 0.707 & 0.098 \\
Durolane [17] & 0.609 & 0.693 & 0.085 \\
Hyalgan [18] & 0.677 & 0.750 & 0.073 \\
\hline
\end{tabular}

QALY quality-adjusted life years 
Table 3 Cost-utility ratios for different brands of iA-HA

\begin{tabular}{|c|c|c|c|c|c|c|}
\hline Brand & $\begin{array}{l}\text { Number of } \\
\text { injections }\end{array}$ & $\begin{array}{l}\text { Cost of HA } \\
\text { product }\end{array}$ & $\begin{array}{l}\text { Cost per } 6 \\
\text { months } \\
(\text { USD })^{\mathbf{a}}\end{array}$ & $\begin{array}{l}\text { QALY gained } \\
\text { per } 6 \text { months }\end{array}$ & $\begin{array}{l}\text { Cost per QALY } \\
\text { gained (USD) })^{\mathbf{b}}\end{array}$ & $\begin{array}{l}\text { ICER vs } \\
\text { conventional } \\
\operatorname{care}^{c}(/ \text { QLY })\end{array}$ \\
\hline Euflexxa & 3 & $\$ 290$ & $\$ 838.90$ & 0.145 & $\$ 5785.52$ & $\$ 4499.13$ \\
\hline Supartz $^{\mathrm{d}}$ & 3 & $\$ 210$ & $\$ 758.90$ & 0.095 & $\$ 7743.88$ & $\$ 6420.80$ \\
\hline Synvisc & 3 & $\$ 525$ & $\$ 1073.90$ & 0.124 & $\$ 8660.48$ & $\$ 8004.25$ \\
\hline Durolane & 1 & $\$ 250$ & $\$ 676.62$ & 0.085 & $\$ 7960.23$ & $\$ 6481.67$ \\
\hline Hyalgan $^{\mathrm{d}}$ & 3 & $\$ 111$ & $\$ 659.90$ & 0.073 & $\$ 9039.73$ & $\$ 7869.77$ \\
\hline $\begin{array}{l}\text { Conventional } \\
\text { care }\end{array}$ & N/A & N/A & $\$ 321.50$ & 0.03 & $\$ 10,716.67$ & - \\
\hline
\end{tabular}

$I A$ intra-articular, $H A$ hyaluronic acid, $Q A L Y$ quality-adjusted life years, ICERs Incremental cost-effectiveness ratios

${ }^{a}$ Cost per 6 months includes the cost of the HA product, plus the cost of a doctor's visit (\$43.98) and the cost of an injectable drug administration $(\$ 61.14)$ for each injection required

${ }^{\mathrm{b}}$ Cost per QALY gained determined by the formula (Cost per 6 months)/(QALY gained per 6 months)

${ }^{c}$ ICER vs conventional care determined by the formula (Cost per 6 months $\mathrm{HA}_{\mathrm{HA}}-$ Cost per 6 months conventional care $_{\text {) }}$ (QALY

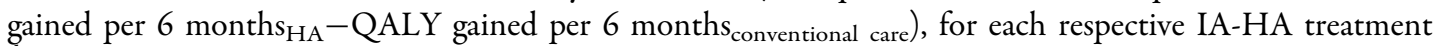

d Three-injection regimens were used in the retrieved studies; however, the indications for these products list a five-injection regimen, which may increase cost

\section{Compliance with Ethics Guidelines}

This article is based on previously conducted studies and does not involve any new studies of human or animal subjects performed by any of the authors.

\section{RESULTS}

\section{Utility Scores}

The utility score of patients who received Euflexxa improved by 0.145 QALY, increasing from 0.482 QALY before treatment to 0.627 QALY after treatment at 6 months (Table 2). Utility scores for Synvisc improved to 0.685 QALY post-treatment from 0.561 QALY pre-treatment for a mean change of 0.124 QALY. Supartz utility scores changed by 0.098 QALY, going from 0.609 QALY at baseline to 0.707 QALY after treatment, while Durolane improved from a mean of 0.609 QALY to 0.693
QALY following treatment, an increase of 0.085 QALY. Finally, Hyalgan on average improved to 0.750 QALY from 0.677 QALY following treatment, a change of 0.073 QALY.

\section{Cost-Utility}

The cost-utility ratios for the five products compared to baseline values ranged from \$5785.52/QALY gained for Euflexxa to \$9039.73/QALY gained for Hyalgan (Table 3). The other three products, Supartz, Synvisc and Durolane, had cost-utility ratios of $\$ 7743.88$ / QALY gained, \$8660.48/QALY gained and $\$ 7960.23 /$ QALY gained, respectively.

The estimated cost of 6 months of conventional care with NSAIDS, physiotherapy, ambulatory aids and acetaminophen was $\$ 321.50$ with a utility score of 0.03 QALY gained [2]. Therefore, the cost-utility for conventional care was $\$ 10,716.67 /$ QALY gained (0.03 QALY * 
Table 4 Incremental cost-effectiveness ratios of Euflexxa vs. other IA-HA brands

\begin{tabular}{llllll}
\hline Brand & $\begin{array}{l}\text { QALY gained } \\
\text { from treatment }\end{array}$ & $\begin{array}{l}\text { Incremental } \\
\text { effectiveness } \\
\text { of Euflexxa } \\
(\text { QALY) }\end{array}$ & Cost (USD) & $\begin{array}{l}\text { Incremental cost of } \\
\text { Euflexxa (USD) }\end{array}$ & ICER $^{\mathbf{b}}$ \\
\hline Euflexxa & 0.145 & - & $\$ 838.90$ & - & - \\
Synvisc & 0.124 & 0.021 & $\$ 1073.90$ & $-\$ 235.00$ & DOMINATED \\
Supartz & 0.095 & 0.05 & $\$ 758.90$ & $\$ 80.00$ & $\$ 1615.67 /$ QALY \\
Durolane & 0.085 & 0.06 & $\$ 676.62$ & $\$ 162.28$ & $\$ 1604.35 /$ QALY \\
Hyalgan & 0.073 & 0.072 & $\$ 659.90$ & $\$ 179.00$ & $\$ 1366.41 /$ QALY \\
\hline
\end{tabular}

$I A$ intra-articular, $H A$ hyaluronic acid, $Q A L Y$ quality-adjusted life years, ICERs incremental cost-effectiveness ratios

${ }^{\text {a }}$ Incremental effectiveness of Euflexxa for each respective IA-HA treatment was determined by the formula

(QALY gained Euflexxa $)-($ QALY gained IA-HA Treatment $)$

$\mathrm{b}$ Incremental cost of Euflexxa for each respective IA-HA treatment was determined by the formula

$\left(\right.$ Cost $\left._{\text {Euflexxa }}\right)-\left(\right.$ Cost $\left._{\text {IA-HA Treatment }}\right)$

c ICER determined by the formula: (incremental cost of Euflexxa)/(incremental effectiveness of Euflexxa)

$33.33=1 \quad$ QALY gained, thus 321.50 * $33.33=\$ 10,716.67$ per 1 QALY gained). All five treatments proved to be cost-effective compared to conventional care, assuming a willingness-to-pay ratio of $\$ 50,000 /$ QALY (Table 3). All HA products had ICERs below the willingness-to-pay threshold when compared to conventional care, with values of \$4499.13/QALY for Euflexxa, \$6420.80/QALY for Supartz, \$8004.25/QALY for Synvisc, \$6481.67/QALY for Durolane and \$7869.77/ QALY for Hyalgan.

When comparing the IA-HA injections, Euflexxa was found to have the most favorable cost-utility ratio. Euflexxa was also found to be the most cost-effective product and was thus used as the baseline comparator. Euflexxa was found to be cost-effective within a willingness-to-pay threshold of \$50,000/QALY when compared to Supartz (\$1615.67/QALY), Durolane (\$1604.35/QALY) and Hyalgan (\$1366.41/QALY). When compared to Synvisc, Euflexxa was the dominant treatment strategy as it provided a greater QALY improvement and was also less expensive (Table 4).

\section{Sensitivity Analysis}

Sensitivity analysis was conducted using two methods, by adjusting the price as well as the utility scores of HA products by $\pm 20 \%$, respectively. Acceptable cost-utility for all five products did not change when cost or utility score was changed by either increasing or decreasing by $20 \%$, as all products remained below the willingness-to-pay threshold of \$50,000/QALY gained (Table 5). Euflexxa retained the lowest cost-utility ratio across all analyses, and Hyalgan had the highest cost-utility ratio across all analyses.

When examining the ICERs compared to conventional care, the sensitivity analysis revealed no changes within the relationships between any HA product and conventional care when adjustments were made to cost of treatment or the product utility score. Differences were seen in the ICER when comparing Euflexxa to other HA products; however, across all sensitivity analyses, Euflexxa remained a cost-effective option (Table 6). Results of cost-effectiveness did not 
Table 5 Sensitivity analysis of cost-utility and incremental cost-effectiveness ratios for different HA products

\begin{tabular}{|c|c|c|c|c|c|c|}
\hline & Brand & Adjustment & $\begin{array}{l}\text { Treatment } \\
\text { cost (USD) }\end{array}$ & Utility score & $\begin{array}{l}\text { Cost per } \\
\text { QALY gained }\end{array}$ & $\begin{array}{l}\text { ICER vs. } \\
\text { conventional } \\
\text { care } \\
\text { (/QALY) }\end{array}$ \\
\hline \multirow[t]{10}{*}{ Treatment cost sensitivity analysis } & Euflexxa & High & $\$ 1006.68$ & 0.145 & $\$ 6942.62$ & $\$ 5958.09$ \\
\hline & & Low & $\$ 671.12$ & & $\$ 4628.41$ & $\$ 3040.17$ \\
\hline & Synvisc & High & $\$ 1288.68$ & 0.124 & $\$ 10,392.5$ & $\$ 10,289.15$ \\
\hline & & Low & $\$ 859.12$ & & $\$ 6928.39$ & $\$ 5719.36$ \\
\hline & Supartz & High & $\$ 910.68$ & 0.098 & $\$ 9281.06$ & $\$ 8664.41$ \\
\hline & & Low & $\$ 607.12$ & & $\$ 6187.38$ & $\$ 4200.29$ \\
\hline & Durolane & High & $\$ 811.94$ & 0.085 & $\$ 9576.13$ & $\$ 8917.16$ \\
\hline & & Low & $\$ 541.30$ & & $\$ 6384.08$ & $\$ 3996.29$ \\
\hline & Hyalgan & High & $\$ 791.88$ & 0.07 & $\$ 11,312.57$ & $\$ 10,939.07$ \\
\hline & & Low & $\$ 527.92$ & & $\$ 7541.71$ & $\$ 4800.46$ \\
\hline \multirow[t]{10}{*}{ Utility score sensitivity analysis } & Euflexxa & High & $\$ 838.90$ & 0.174 & $\$ 4821.26$ & $\$ 3593.06$ \\
\hline & & Low & & 0.116 & $\$ 7231.90$ & $\$ 6016.28$ \\
\hline & Synvisc & High & $\$ 1073.90$ & 0.149 & $\$ 7217.07$ & $\$ 6333.33$ \\
\hline & & Low & & 0.099 & $\$ 10,825.60$ & $\$ 10,872.83$ \\
\hline & Supartz & High & $\$ 758.90$ & 0.118 & $\$ 6445.18$ & $\$ 4984.79$ \\
\hline & & Low & & 0.078 & $\$ 9667.77$ & $\$ 9018.95$ \\
\hline & Durolane & High & $\$ 676.62$ & 0.102 & $\$ 6650.09$ & $\$ 4949.68$ \\
\hline & & Low & & 0.068 & $\$ 9975.13$ & $\$ 9387.09$ \\
\hline & Hyalgan & High & $\$ 659.90$ & 0.084 & $\$ 7855.95$ & $\$ 6266.67$ \\
\hline & & Low & & 0.056 & $\$ 11,783.93$ & $\$ 6016.28$ \\
\hline
\end{tabular}

$H A$ hyaluronic acid, $Q A L Y$ quality-adjusted life years, ICERs incremental cost-effectiveness ratios

change when the cost of Euflexxa was increased by $20 \%$; however, when reduced by $20 \%$, Euflexxa became a dominant treatment option compared to Supartz and Durolane, in addition to Synvisc. Euflexxa did not become dominant over any additional treatments when the cost-utility was increased by $20 \%$. When the cost-utility was decreased by $20 \%$, Euflexxa was no longer a dominant treatment over Synvisc, but it was still a cost-effective treatment option, with an ICER of \$29,375.00/QALY gained.

\section{DISCUSSION}

The purpose of this study was to determine how the cost-effectiveness of various IA-HA products differs from one another, and to also compare the cost-effectiveness results to those of conventional care for knee OA. This study 
Table 6 Sensitivity analysis of incremental cost-effectiveness ratios of Euflexxa vs. other IA-HA brands

\begin{tabular}{|c|c|c|c|c|c|c|c|c|c|}
\hline & \multirow[t]{2}{*}{ Brand } & \multirow[t]{2}{*}{$\begin{array}{l}\text { Product } \\
\text { cost }\end{array}$} & \multirow{2}{*}{$\begin{array}{l}\text { Product } \\
\text { utility } \\
\text { score }\end{array}$} & \multicolumn{2}{|c|}{ Euflexxa cost } & \multicolumn{2}{|c|}{$\begin{array}{l}\text { Euflexxa } \\
\text { utility score }\end{array}$} & \multicolumn{2}{|c|}{$\begin{array}{l}\text { ICER (Euflexxa vs. HA } \\
\text { product) }\end{array}$} \\
\hline & & & & $\overline{\text { High }}$ & Low & High & Low & High & Low \\
\hline \multirow{4}{*}{$\begin{array}{l}\text { Euflexxa cost } \\
\text { sensitivity analysis }\end{array}$} & Synvisc & $\$ 1073.90$ & 0.124 & $\$ 1006.68$ & $\$ 671.12$ & 0.145 & & Dominated & Dominated \\
\hline & Supartz & $\$ 758.90$ & 0.098 & $\$ 1006.68$ & $\$ 671.12$ & 0.145 & & $\begin{array}{c}\$ 5285.68 / \\
\text { QALY }\end{array}$ & Dominated \\
\hline & Durolane & $\$ 676.62$ & 0.085 & $\$ 1006.68$ & $\$ 671.12$ & 0.145 & & $\begin{array}{c}\text { \$5481.66/ } \\
\text { QALY }\end{array}$ & Dominated \\
\hline & Hyalgan & $\$ 659.90$ & 0.073 & $\$ 1006.68$ & $\$ 671.12$ & 0.145 & & $\begin{array}{c}\$ 4623.73 / \\
\text { QALY }\end{array}$ & $\begin{array}{r}\$ 149.60 / \\
\text { QALY }\end{array}$ \\
\hline \multirow[t]{4}{*}{$\begin{array}{r}\text { Euflexxa utility score } \\
\text { sensitivity analysis }\end{array}$} & Synvisc & $\$ 1073.90$ & 0.124 & $\$ 838.90$ & & 0.174 & 0.116 & Dominated & $\begin{array}{l}\$ 29,375.00 / \\
\text { QALY }\end{array}$ \\
\hline & Supartz & $\$ 758.90$ & 0.098 & $\$ 838.90$ & & 0.174 & 0.116 & $\begin{array}{c}\$ 1054.33 / \\
\text { QALY }\end{array}$ & $\begin{array}{c}\$ 4474.87 / \\
\text { QALY }\end{array}$ \\
\hline & Durolane & $\$ 676.62$ & 0.085 & $\$ 838.90$ & & 0.174 & 0.116 & $\begin{array}{l}\$ 1819.04 / \\
\text { QALY }\end{array}$ & $\begin{array}{l}\$ 5199.34 / \\
\text { QALY }\end{array}$ \\
\hline & Hyalgan & $\$ 659.90$ & 0.073 & $\$ 838.90$ & & 0.174 & 0.116 & $\begin{array}{c}\$ 1772.28 / \\
\text { QALY }\end{array}$ & $\begin{array}{c}\$ 4162.79 / \\
\text { QALY }\end{array}$ \\
\hline
\end{tabular}

$I A$ intra-articular, $H A$ hyaluronic acid, $Q A L Y$ quality-adjusted life years, ICERs incremental cost-effectiveness ratios

${ }^{a}$ ICER determined by the formula: (incremental cost of Euflexxa)/(incremental effectiveness of Euflexxa)

followed a stepwise approach in performing a cost analysis. Initial cost-utility ratios were calculated to determine the cost for gaining one QALY for each IA-HA product. This was followed by determining the ICERs compared to conventional care, demonstrating the cost-effectiveness of each brand compared to that of patients receiving 6 months of conventional care alone. Finally, comparative ICERs were calculated, demonstrating the cost-effectiveness among the IA-HA treatments.

It was found that Euflexxa had the lowest cost-utility ratio of all the treatments at \$5785.52/QALY gained when compared to no treatment, while Hyalgan had the highest cost-utility ratio at $\$ 24,171.43 / \mathrm{QALY}$ gained. It was also determined that Euflexxa, Synvisc and Supartz were cost-effective options over conventional care assuming a willingness-to-pay threshold of \$50,000/QALY. When comparing Euflexxa to all other IA-HA brands, Euflexxa is a cost-effective option over Hyalgan, Supartz and Durolane assuming a willingness-to-pay threshold of \$50,000/QALY, and was a dominant treatment strategy over Synvisc.

The need for cost-effective treatments for knee $\mathrm{OA}$ is extremely important due to the increasing prevalence and incidence of the disease, which will create an increasingly large burden upon the healthcare system in the United States [1-4]. With the high cost of primary TKA and even higher cost of revision TKA, a cost-effective treatment which can delay 
the need for arthroplasty would help to relieve some of the economic burden imposed by knee OA. HMW, Bio-HA has the potential to provide a cost-effective option to provide relief of knee OA symptoms and delay the need for TKA [9, 10, 13, 14].

IA corticosteroid injections are another potential treatment strategy to address knee OA, and may hold benefits similar to IA-HA with respect to symptom control and need for TKA. This would have been an informative treatment comparison; however, there is a lack of existing data on corticosteroid investigations including all three components of the WOMAC in the five-point Likert format. The focus of future research in this area would provide valuable outcome information and allow for a more thorough cost analysis of IA-HA.

There are several limitations to this study. Only randomized controlled trials that reported all three components of the WOMAC in the five-point Likert format (not in the $100 \mathrm{~mm}$ VAS) were included, as all three are required to acquire the HUI-3 utility scores from the formulas by Grootendorst [15]. This limited the number of studies that could be included in the analysis, as a majority of studies report only specific sections of the WOMAC, or present WOMAC findings in an unusable format. Only studies presenting WOMAC were used to derive HUI-3 scores, as opposed to deriving utility scores from different knee or quality of life measures, in an attempt to control for variation that may be caused using different measurement tools. The Grootendorst method to derive utility outcomes from WOMAC scores is dependent on the accuracy and applicability of the model used [15]. Furthermore, the trials used to derive HUI-3 scores involved patient groups which may vary from one another in several aspects, such as location and year of the studies, which could potentially influence the results. We also assumed that patients receiving IA-HA would also receive conventional care in its full capacity. Patients receiving IA-HA would still potentially receive aspects of conventional care such as acetaminophen or physiotherapy; however, they may not receive as much additional treatment as a patient who did not receive IA-HA. This potential decrease in the need for conventional care would likely lead to an improvement in the cost-utility of HA products, as well as their respective ICERs when compared to conventional care. An additional limitation stems from the potential for differences between patient demographics within the included studies. It is also of note that these products vary with respect to intrinsic properties, such as molecular weight and production process. These differences may attribute to the varying outcomes for each specific product, suggesting it may not be appropriate to consider all HA products as equal. This study is strengthened by the sensitivity analysis conducted, which confirmed the robustness of the results. The sensitivity analysis revealed no changes in the ICERs of HA products in comparison to conventional care.

This cost analysis represents a single payer, base case scenario and does not take into consideration additional costs related to adverse effects and additional treatments due to the use of specific products. However, this consideration would possibly prove Euflexxa to be beneficial when compared to the other IA-HA products, as there has been some evidence that Bio-HA products are associated with fewer injection site adverse reactions, and may have fewer costs related to adverse effects [11]. The present study assumed that two of the products would require a three-injection regimen as this is what was used in the retrieved studies. However, the prescribing 
information for these two products (Hyalgan and Supartz) lists a five-injection regimen, which may have an influence on the cost-effectiveness of these products. A willingness-to-pay threshold of $\$ 50,000$ has been utilized out of convention; however, there has been suggestion of the use of a more appropriate threshold of $\$ 100,000$ [27].

\section{CONCLUSION}

In conclusion, IA-HA can be a cost-effective treatment compared to no treatment and also to conventional care. The comparison of cost-effectiveness across available HA brands demonstrated that Euflexxa had the lowest cost-utility ratio of all investigated HA products. To validate these findings, additional clinical trials which include all components of the WOMAC should be conducted to provide more thorough data for the derivation of utility scores.

\section{ACKNOWLEDGMENTS}

Sponsorship, medical writing, article processing charges, and the open access charge for this study were funded by Ferring Pharmaceutics Inc.

All authors had full access to all of the data in this study and take complete responsibility for the integrity of the data and accuracy of the data analysis.

Medical writing assistance for this study was provided by Mark Phillips and Global Research Solutions Inc.

All named authors meet the International Committee of Medical Journal Editors (ICMJE) criteria for authorship of this manuscript, take responsibility for the integrity of the work as a whole, and have given final approval for the version to be published.
Disclosures. Jeffrey Rosen Serves on the Advisory Board for Ferring Pharmaceuticals Inc. Anke Fierlinger is a paid employee of Ferring Pharmaceuticals Inc.

Faizan Niazi is a paid employee of Ferring Pharmaceuticals Inc.

Asheesh Bedi is a consultant for Arthrex, Inc., and stock/stock options with A3 Surgical.

Parag Sancheti and Herman Johal have nothing to disclose.

Compliance with Ethics Guidelines. This article is based on previously conducted studies and does not involve any new studies of human or animal subjects performed by any of the authors.

Open Access. This article is distributed under the terms of the Creative Commons Attribution-NonCommercial 4.0 International License (http://creativecommons.org/licenses/ by-nc/4.0/), which permits any noncommercial use, distribution, and reproduction in any medium, provided you give appropriate credit to the original author(s) and the source, provide a link to the Creative Commons license, and indicate if changes were made.

\section{REFERENCES}

1. Bitton R. The economic burden of osteoarthritis. Am J Manag Care. 2009;15(8 Suppl):S230-5.

2. Losina E, Daigle ME, Reichmann WM, et al. Disease-modifying drugs for knee osteoarthritis: can they be cost-effective? Osteoarthr Cartil. 2014;21(5):655-67.

3. Centres for Disease Control and Prevention (CDC). National and state medical expenditures and lost earnings attributable to arthritis and other rheumatic conditions-United States, 2003. Morb Mortal Wkly Rep. 2007;56(1):4-7.

4. Zhang Y, Jordan J. Epidemiology of osteoarthritis. Clin Geriatr Med. 2010;26(3):355-69. 
5. Hochberg MC, Altman RD, April KT, et al. American College of Rheumatology 2012 recommendations for the use of nonpharmacologic and pharmacologic therapies in osteoarthritis of the hand, hip, and knee. Arthritis Care Res. 2012;64(4):465-74.

6. Losina E, Paltiel D, Weinstein AM, et al. Lifetime medical costs of knee osteoarthritis management in the United States: impact of extending indications for total knee arthroplasty. Arthritis Care Res (Hoboken). 2015;67(2):203-15.

7. HCUPnet. National statistics on all stays: 2012 outcomes by patient and hospital characteristics for ICD-9-CM principal procedure code 81.54 total knee replacement. [A conventional caressed April 24, 2015].

8. Dy CJ, Marx RG, Bozic KJ, Pan TJ, Padgett DE, Lyman S. Risk factors for revision within 10 years of total knee arthroplasty. Clin Orthop Relat Res. 2014;472(4):1198-207.

9. Waddell DD, Bricker DC. Total knee replacement delayed with Hylan G-F 20 use in patients with grade IV osteoarthritis. J Manag Care Pharm. 2007;13(2):113-21.

10. Karatosun V, Unver B, Gocen Z, Sen A. Comparison of two hyaluronan drugs in patients with advanced osteoarthritis of the knee. A prospective, randomized, double-blind study with long term follow-up. Clin Exp Rheumatol. 2004;23(2):213-8.

11. Kirchner M, Marshall D. A double-blind randomized controlled trial comparing alternate forms of high molecular weight hyaluronan for the treatment of osteoarthritis of the knee. Osteoarthr Cartil. 2006;14:154-62.

12. Berenbaum F, Grifka J, Cazzaniga S, et al. A randomised, double-blind, controlled trial comparing two intra-articular hyaluronic acid preparations differing by their molecular weight in symptomatic knee osteoarthritis. Ann Rheum Dis. 2012;71:1454-60.

13. Hatoum HT, Fierlinger AL, Lin S-J, Altman RD. Cost-effectiveness analysis of intra-articular injections of a high molecular weight bioengineered hyaluronic acid for the treatment of osteoarthritis knee pain. J Med Econ. 2014;17(5):326-37.

14. Torrance GW, Raynauld JP, Walker V, et al. A prospective, randomized, pragmatic, health outcomes trial evaluating the incorporation of hylan G-F 20 into the treatment paradigm for patients with knee osteoarthritis (Part 2 of 2): Economic results. Osteoarthr Cartil. 2002;10(7):518-27.
15. Grootendorst P, Marshall D, Pericak D, Bellamy N, Feeny D, Torrance GW. A model to estimate health utilities index mark 3 utility scores from WOMAC index scores in patients with osteoarthritis of the knee. J Rheumatol. 2007;34(3):534-42.

16. Karlsson J, Sjögren LS, Lohmander LS. Comparison of two hyaluronan drugs and placebo in patients with knee osteoarthritis. A controlled, randomized, double-blind, parallel-design multicentre study. Rheumatol. 2002;41(11):1240-8.

17. Altman RD, Akermark C, Beaulieu AD, Scnitzer T, et al. Efficacy and safety of a single intra-articular injection of non-animal stabilized hyaluronic acid (NASHA) in patients with osteoarthritis of the knee. Osteoarthr Cartil. 2004;12(8):642-9.

18. DeCaria J, Montero-Odasso M, Wolfe D, Chesworth B, Petralla R. The effect of intra-articular hyaluronic acid treatment on gait velocity in older knee osteoarthritis patients: a randomized, controlled study. Arch Gerontol Geriatr. 2012;55(2):310-5.

19. Day R, Brooks P, Conaghan PG, Petersen M, et al. A double blind, randomized, multicentre, parallel group study of the effectiveness and tolerance of intraarticular hyaluronan in osteoarthritis of the knee. J Rheumatol. 2004;31(4):775-82.

20. Altman RD, Rosen JE, Bloch D, Hatoum HT, Korner P. A double-blind, randomized, saline-controlled study of the efficacy and safety of EUFLEXXA for treatment of painful osteoarthritis of the knee, with an open-label safety extension (The FLEXX Trial). Semin Arthritis Rheum. 2009;39(1):1-9.

21. Higgins J, Green S. Cochrane handbook for systematic reviews of interventions version 5.1.0 [updated March 2011]. The Cochrane Collaboration; 2011.

22. Raynauld JP, Torrance GW, Band PA, et al. A prospective, randomized, pragmatic, health outcomes trial evaluating the incorporation of hylan G-F 20 into the treatment paradigm for patients with knee osteoarthritis (Part 1 of 2): clinical results. Osteoarthr Cartil. 2002;10(7):506-17.

23. Centres for Medicare \& Medicaid Services. Physician fee schedule look-up. Baltimore. http:// cms.hhs.gov/PFSlookup/. A conventional careessed April 22, 2015.

24. Club MD. clubmd.biz/products/index/4/ orthopaedics.html. A conventional careessed April 24, 2015.

25. Braithwaite RS, Meltzer DO, King JT, Leslie D, Roberts MS. What does the value of modern medicine say about the $\$ 50,000$ per 
quality-adjusted life-year decision rule? Med Care. 2008;46(4):349-56.

26. Ubel P, Hirth R, Chernew ME, Fendrick M. What is the price of life and why doesn't it increase at the rate of inflation? Arch Intern Med. 2003;163(14):1637-41.
27. Neumann PJ, Cohen JT, Weinstein MC. Updating cost-effectiveness-the curious resilience of the \$50,000-per-QALY threshold. N Engl J Med. 2014;371(9):796-7. 